\title{
Spatial Metabolism of Urban Densities: Integument of Bangalore, India
}

\author{
Shubhi S, Santhanam Kumar
}

\begin{abstract}
Rising population density in our cities is one of the major challenges unleashed by rampant urbanisation. In the western world the urbanisation is often linked to the phenomenon of urban sprawl. However, in the developing world, lack of transportation linkages and poor infrastructure in the peri urban areas makes sprawl an unattractive proposition. Even as cities continue to expand, the inner city neighbourhoods are being continuously intensified in terms of population and dwelling units. Density is a term which is used repeatedly in urban discourses. The paper aims at delineating the concept of density into its diverse metrics. The density metrics are evaluated and examined to reveal their inter relationships and interactions with the city structure. A spatial analysis of diverse high density metrics is carried out for Bangalore city. The study helps in enhancing our understanding of density and its interactions with the spatial structure of the city

Keywords - High Density neighborhoods, correlation, Spatial analysis,
\end{abstract}

\section{INTRODUCTION}

Most discourses on urban development and planning find a fleeting mention of density. Density plays multifarious roles in the urban realm. It is known to be a cause, effect as well as silent catalyst in the urban metabolic processes. This paper aims to develop a deeper understanding of urban density and its manifestations. Various methods of evaluating urban density are explored and compared to arrive at a macro level analysis of density- city structure interactions.

As urbanisation pulls more people towards our already crowded cities, it is not merely density but "high density" that has become a matter of concern. Even as researchers debate the evils of high density compact living, the cultural and socioeconomic milieu makes it an evident ground reality in Asian cities. A detailed understanding of density manifestations and spatial interactions with the city structure can enhance our efforts towards creating liveable density in our cities. This paper attempts to answer the following questions:

i. What are the various forms in which density manifests itself in the city?

ii. Are there interrelationships between the various types of densities?

iii.Is there a spatial pattern to the occurrence of high densities in the city?

iv. Do the densities interact with spatial structure of the city?

The study is based in the garden city of Bangalore, India. Bangalore is the capital of the southern state of Karnataka in

Revised Manuscript Received on April 12, 2019.

Shubhi S, School of Architecture REVA University Bangalore, Karnataka, India. (shubhisonal@ reva.edu.in)

Santhanam Kumar, School of Planning and Architecture JNAFA University Hyderabad, Telangana, India. (skumarjnafau.gmail.com)
India. Bangalore has the dubious distinction of being the fastest growing city in India. The census 2011 data shows a massive $46.68 \%$ decadal growth rate of population for the city. Promising job opportunities, supply of skilled labour and salubrious climate is pulling people from all over the country as well as abroad to come and settle in the city. As the city gears up to accommodate population much beyond its meagre capacity there are serious doubts on the quality of life on offer to the residents. People choice of residential location depends on multiple factors such as accessibility, level of infrastructure provision, area attractiveness. The largely mono centric city structure also appears to play a crucial role in density distribution across the city.

\section{DELINEATING THE CONCEPT OF DENSITY}

The concept of density is frequently used to describe the relationship between an area and the number of certain entities in that area. These entities might be people, dwellings, services, or floor space. Urban density can be expressed in many ways. A widely used measurement is the number of dwelling units per unit area (acre, hectare). This measurement gives only information about the number of dwellings, not about their size or the way they are grouped. More general and precise ways of measuring density are measurements based on built area or gross floor area, respectively named ground space index and floor area ratio [13]. Researchers identify the ambiguity in the term and point out that the ambiguity can be attributed to differences in the base area used for calculation as well as the attribute measured[7][3]. Roberts, B. [22] further categorized density as demographic, spatial, mass, utility, time space and perceived density. The term perceived density is an interesting concept first introduced in the seminal works of Amos Rapoport [14]. It distinguishes itself from physical density since it is based on individual apprehension. While physical density can be seen as a neutral quantitative indicator, perceived density is also deemed to neutral subjective as it represents the socio cultural ethos of the people residing in an area [4].The subjective nature of density was further corroborated by Friedman [8] where he stated that density relates to a particular location and culture.

\section{A. Defining density and its types}

Literature abounds with definitions and examples of manifestations of density based on various contexts, scale and other factors. After review of relevant literature in the field the definitions were arranged in order to generate a simplified taxonomy for the term density. To begin with 
density may be simply defined as the number of units in a given area. The various types of density strewn across research literature can be grouped based on the attribute measured, level of quantification, purpose and tangibility. The category-"Attribute measured" was selected to proceed with formulation of density metrics for Bangalore city.

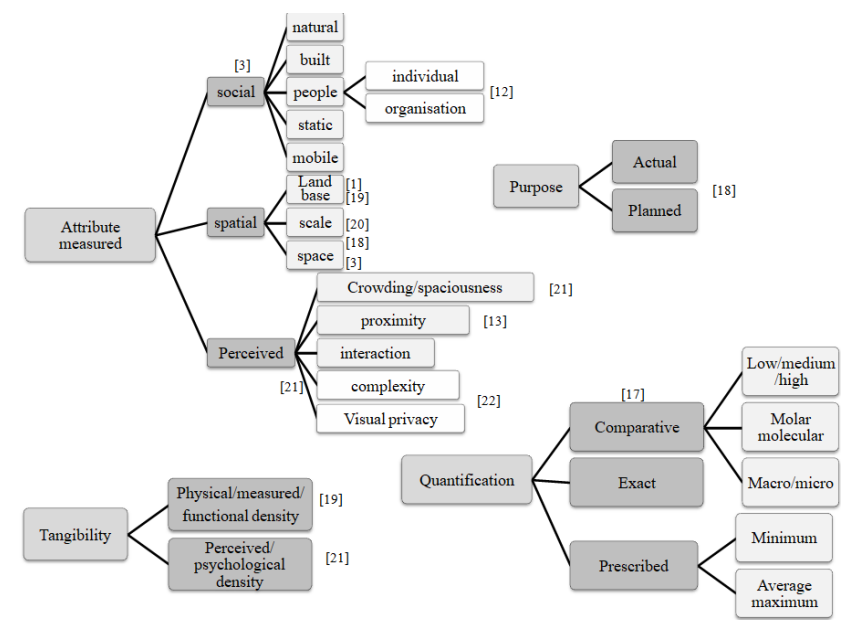

Figure 1. Compilation of density measures from research literature.

Source: author

\section{DATA PREPARATION AND ANALYSIS}

Urban density can be best described if we have measures which deal with social, spatial as well as the perceived density of the city. Social density includes measures related to population as well as the built environment. Population density data is readily available from the census 2011 for Bangalore. Built density gives an idea of the intensity of land use and overall urban form in an area. Indian cities with the exception of Mumbai and peripheral areas in NCR Delhi operate on the low/mid rise- high density model of urban built form. In such a scenario it is quite interesting to observe the spread of high rise structures in the city as it gives an indication of a visible transformation in the urban form. High rise urban density may hence be defined as number of high rise built structures per unit area. The census 2011 enumerates the wardwise distribution of high rise structures( buildings $>\mathrm{G}+3$ ).

Compactness ratio [2] is an indirect urban form related metric of urban density. Compactness ratio is used to distinguish between dispersed and compact areas and hence can give us a better idea of concentration of dwelling units in an area.

The concept of perceived density finds several mentions in research literature [21] [13] [5] [9]. Perceived density finds manifestations in form of crowding/spaciousness measures, proximity variables and levels of interactions. While standard population density measures the amount of land surrounding each resident of a city, perceived density can quantify the average number of people around each resident of that city. Eidlin, E. [6] explains the method of calculating perceived density of an area as a weighted metric reflecting the share of the city's population contained in a census tract. As opposed to standard population density which measures concentration of land around an individual, perceived density measures the average number of people around each resident of a city.

TABLE 1 DENSITY METRICS

\begin{tabular}{|c|c|c|}
\hline $\begin{array}{l}\text { Density } \\
\text { Metric }\end{array}$ & Formulae & Units \\
\hline $\begin{array}{l}\text { Standard } \\
\text { Population } \\
\text { density }\end{array}$ & $\begin{array}{l}d_{s} \\
=\frac{\text { total population }}{\text { total area of census tract }}\end{array}$ & $\begin{array}{l}\text { Persons } \\
\text { per } \\
\text { sq.km }\end{array}$ \\
\hline $\begin{array}{l}\text { High Rise } \\
\text { built } \\
\text { density }\end{array}$ & $\begin{array}{l}d_{h} \\
=\frac{\text { no. of buildings higher tha }}{\text { total area of census tr }}\end{array}$ & $\begin{array}{l}\text { Buildin } \\
\text { gs per } \\
\text { sq.km }\end{array}$ \\
\hline $\begin{array}{l}\text { Compactne } \\
\text { ss Ratio }\end{array}$ & $\begin{array}{l}\boldsymbol{d}_{\boldsymbol{c r}}=\frac{\boldsymbol{H}_{\boldsymbol{i}} / \sum \boldsymbol{H}}{\boldsymbol{B u}_{\boldsymbol{i}} / \sum \boldsymbol{B u}} \\
\text { Where, } \\
H_{i}=\text { Total dwelling units in a } \\
\text { ward } \\
\sum H=\text { Dwelling units in all wards } \\
B u_{i}=\text { Total Built up area in ward } \\
\sum B u=\text { Total Built up area in all } \\
\text { wards }\end{array}$ & nil \\
\hline $\begin{array}{l}\text { Perceived } \\
\text { density }\end{array}$ & $\begin{array}{l}\boldsymbol{d}_{\boldsymbol{p}}=\boldsymbol{w}_{\boldsymbol{i}} \boldsymbol{X} \boldsymbol{d}_{\boldsymbol{s}} \\
\text { Where, } \\
w_{i}=\text { share of city's population } \\
\text { contained in ward } \\
d_{s}=\text { Standard population density } \\
\text { of the ward }\end{array}$ & $\begin{array}{l}\text { Persons } \\
\text { per } \\
\text { sq.km }\end{array}$ \\
\hline
\end{tabular}

\section{A. Correlation between density metrics}

The abovementioned density metrics were calculated for all 198 wards of Bangalore city. Ward wise Data related to total population and number of buildings higher than Ground plus three storeys was sourced from census 2011. Data available from BBMP website was used to calculate ward areas and total built up areas in each ward. Further analysis of the data was carried out using SPSS. Extent testing indicated linear relationships between the density metrics. As evident from the descriptive statistics, the data sets were non normal distributions. Spearman's correlation analysis was employed to measure of the strength of association between the variables. Spearman's coefficient is a nonparametric (distribution-free) rank statistic proposed by Charles Spearman that measures of a monotonic association between variables [16] [10]. It must also be noted that this analysis does not in any way imply any causal relationship between the variables.

\section{TABLE 2. STATISTICAL ANALYSIS OF DENSITY METRICS USING SPSS}

\begin{tabular}{|l|l|l|l|l|l|l|}
\hline \multicolumn{1}{|l|}{ Descriptive Statistics } & & $\begin{array}{l}\text { Std. } \\
\text { Deviatio } \\
\end{array}$ & & Minim & Maximu & Varianc \\
& $\mathbf{N}$ & $\mathbf{u m}$ & $\mathbf{m}$ & Mean & n \\
\hline $\begin{array}{l}\text { Population } \\
\text { density }\end{array}$ & 198 & 1652 & 118059 & $\begin{array}{l}27501 . \\
26\end{array}$ & $\begin{array}{l}20867.00 \\
1\end{array}$ & $4.354 \mathrm{E} 8$ \\
\hline
\end{tabular}




\begin{tabular}{|l|l|l|l|l|l|l|}
\hline $\begin{array}{l}\text { Perceived } \\
\text { density }\end{array}$ & 198 & 10 & 542 & 131.14 & 101.393 & $\begin{array}{l}10280.53 \\
3\end{array}$ \\
\hline $\begin{array}{l}\text { High rise } \\
\text { built } \\
\text { density }\end{array}$ & 198 & 27 & 3019 & 358.19 & 302.022 & $\begin{array}{l}91217.25 \\
2\end{array}$ \\
\hline $\begin{array}{l}\text { Compactn } \\
\text { ess ratio }\end{array}$ & 198 & .10 & 8.60 & 2.3061 & 1.66089 & 2.759 \\
\hline $\begin{array}{l}\text { Valid N } \\
\text { (listwise) }\end{array}$ & 198 & & & & & \\
\hline
\end{tabular}

A Radar chart was plotted using MS excel to graphically illustrate the interrelationships between the density metrics. Perceived density shows very strong positive correlation with standard population density and compactness ratio. However it shows moderate positive correlation with high rise built density. At the same time, high rise built density shows moderate positive correlation with all other density metrics. The statistical findings shown above were corroborated by carrying out a spatial analysis of high density in Bangalore city.

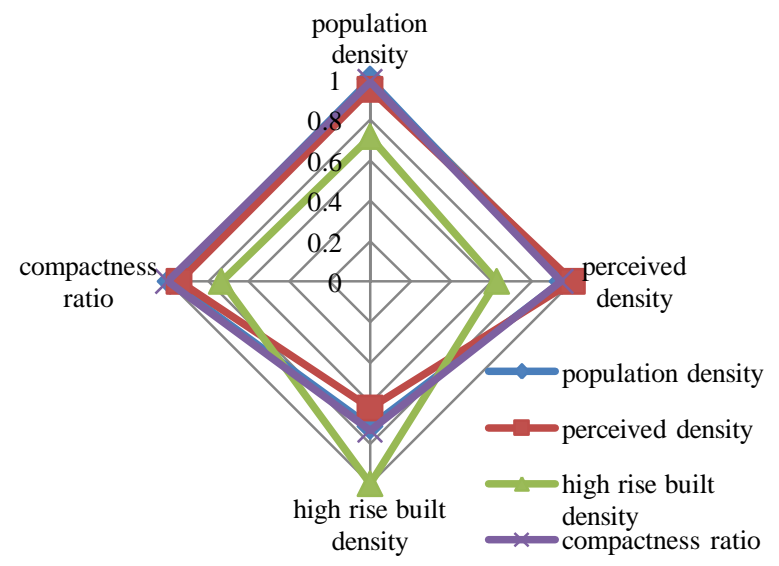

Figure 2: Spearman's correlation coefficient for density metrics

\section{HIGH DENSITY IN THE CITY}

The area of Bangalore wards ranges from a meagre 0.2 sq. $\mathrm{km}$ to as large as $30 \mathrm{sq} . \mathrm{km}$. Also, we find drastic differences in the level of infrastructural development and growth patterns amongst the wards. As we set upon the task of comparing the wards of Bangalore it becomes very clear that in the absence of clear criterion for ward selection we might end up comparing apples and oranges. In order to allocate ranks to the wards based on their density specifications it becomes necessary to choose wards which display similar characteristics as far as size, level of development and growth pattern is concerned. Wards within the area range of 0.8-2 sq.km were selected from the 198 BBMP wards. The selected wards were further filtered down as per criteria of uniform level of infrastructural provision. Wards where percentage of Households with access to municipal water supply was less that $75 \%$ ( city average) were removed from the selection. Further, the wards which have shown a decline in population over the past decades were eliminated as these are areas where residential character of the neighbourhoods has been lost to booming commercial activities. The filtered down list containing 96 wards was then used for further spatial analysis of various types of density metrics in the city.

The four density metrics of Standard population density, perceived density, High rise built density and compactness ratio were computed for the selected wards. Based on the range of values displayed for each density metrics, the wards were allotted grades reflecting their comparative positions. The top graded wards for each density metric were then mapped to analyse the spatial allocation of various types of high densities in Bangalore.

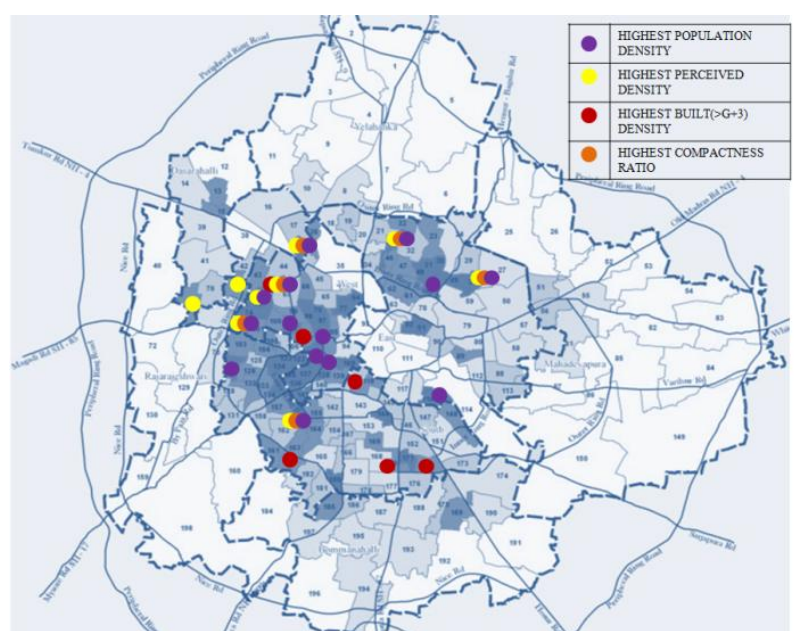

Figure 3. Spatial allocation of various types of high density wards in Bangalore. Source: Authors

\section{A. Observations}

- High population density is observed in the central and west central areas of Bangalore city. This is in consonance with the growth pattern of the city. As expected the Pete and surrounding areas (Binni Pete, Cotton Pete etc.) have high population density. This can be attributed to them being the economic core of the city with large amount of commercial and mixed use activity. Traditional layout comprising of narrow streets and multiple stories (often illegal) can be seen as main perpetrators of high population density in these areas. High population density continues from the centre towards the west between the Magadi road and Tumkur road transport arteries of the city. Again historic and economic factors can be cited as reason for high concentration of population in these areas. This area was also the suburban industrial hub of Bangalore housing many factories, mills and industrial units. The construction of NICE road and the introduction of Metro in this region have further increased the attractiveness of the area for the masses.

- High perceived density is generally coincident with high population density. It is observed that perceived density is higher than actual population density in areas which have marginally lower land value and are primarily occupied by LIG/MIG income groups. High perceived density is also seen to be coincident with high compactness ratio except in the case of planned

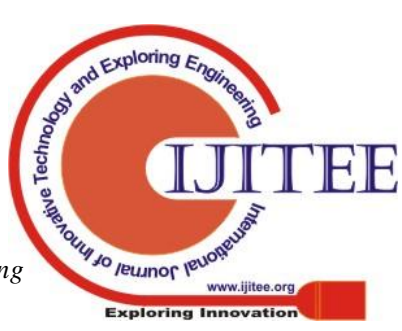


layouts. High perceived density is observed in the central and west central zone. Also we observe sporadic occurrences of high perceived density in wards abutting important transport arteries such as Hennur road and Bellary road.

- High rise $(>G+3)$ built density shows little or no coincidence with perceived density. It may be safely said that in Bangalore, high rise character is associated with medium/low density dispersed areas. High density of high rise structures is observed mostly in the southern wards of the city which include several well planned layouts in and around the inner and outer ring roads. Here the road width, plot sizes and building byelaws make a favorable location for construction of high rise structures. It is also observed compactness ratio is low in the areas which have high density of high rise buildings.

- High compactness ratio almost always occurs in conjunction with perceived and population density. Like other density metrics, high compactness ratio also makes sporadic appearances along important transport arteries of the city such as the inner and outer ring roads.

\section{INTERACTION OF DENSITY TYPES WITH CITY STRUCTURE \& RESULTS}

As we delve deeper into density and its various manifestations in the city, it becomes necessary to evaluate the impact of city structure on density metrics. All the density metrics area measured over a given area. The characteristics of any area may be defined in terms of basic parameters such as size, location, infrastructure availability. Indicators were selected to measure these basic characteristics of an urban area.

Table 3. Selected City structure metrics

\begin{tabular}{|l|l|l|l|}
\hline $\begin{array}{l}\text { City } \\
\text { structure } \\
\text { parameter }\end{array}$ & Indicator & $\begin{array}{l}\text { Data } \\
\text { Source }\end{array}$ & Units \\
\hline Size & Ward Area & BBMP & Sq. meter \\
\hline Location & $\begin{array}{l}\text { Distance } \\
\text { from city } \\
\text { centre } \\
\text { (Majestic } \\
\text { Railway } \\
\text { station) }\end{array}$ & $\begin{array}{l}\text { Calculated } \\
\text { by Author } \\
\text { as per } \\
\text { driving } \\
\text { distance } \\
\text { through } \\
\text { shortest } \\
\text { route }\end{array}$ & Kilometres \\
\hline $\begin{array}{l}\text { Infrastruct } \\
\text { ure } \\
\text { availability }\end{array}$ & $\begin{array}{l}\text { Road } \\
\text { Density }\end{array}$ & BBMP & $\begin{array}{l}\text { Road length } \\
\text { in meters } \\
\text { per sq.km }\end{array}$ \\
\hline
\end{tabular}

Scatter Plots created using SPSS to understand the nature of relationship between the city structure indicators and various density metrics. The plots indicated linear relationships of varying degree between the indicators and density metrics. For more concrete findings, Spearman's correlation analysis was carried out on the data for all 198 wards of Bangalore.
The correlation coefficients generated show a negative relationship between the chosen city structure indicators and density metrics. Density metrics namely standard population density, perceived density, high rise built density and compactness tends to decrease in value as we move away from the city centre. This finding reinforces the fact that Bangalore continues to be a mono centric city. The core areas continue to be highly dense in all respects despite byelaws which aim at controlling density in the core and promoting high density development in the peripheral areas. Recent spurt in growth of peri urban areas may change the scenario in coming years. Radar charts were plotted in MS Excel to further illustrate the correlation between the city structure indicators and density metrics.

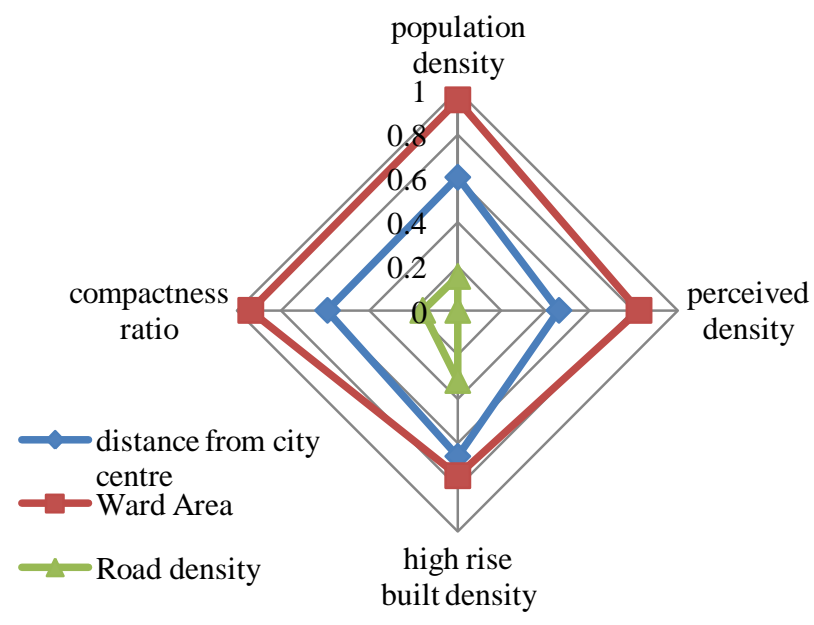

Figure 4. Correlation of density types with city structure metrics. Source: Spearman's correlation generated in SPSS.

\section{CONCLUSIONS}

Ward Area shows maximum correlation with the various metrics of density followed by distance from city centre. The recent reorganisation of Bangalore wards by BBMP based on equitable distribution of population can be seen as the main reason behind this finding. Given that the core areas bear high density pockets as a result of historical and socioeconomic structure of the city, the same have been carved into smaller wards whereas the sparsely populated peripheral areas have been carved into larger wards to equalize the population. Since this was a planned intervention, we cannot hope to deduce much about city structure density dynamics from this correlation. Road density shows zero correlation with perceived density. Nevertheless it shows significant but very weak negative correlation with the other density metrics. The road density in a given ward reflects the infrastructural development and level of connectivity of the ward to the neighbouring areas. It appears that infrastructural development in a ward is guided by factors other than intensity of population or buildings. 


\section{REFERENCES}

1. Angel, Shlomo, et al. "The persistent decline in urban densities: Global and historical evidence of sprawl." Lincoln Institute of Land Policy Working Paper, 2010

2. Bardhan, Ronita, Kiyo Kurisu, and Keisuke Hanaki. "Does compact urban forms relate to good quality of life in high density cities of India? Case of Kolkata." Cities 48, 2015: 55-65.

3. Boyko, Christopher T., and Rachel Cooper, Clarifying and reconceptualising density." Progress in Planning 76.1,2011: 1-61.

4. Cheng, Vicky, "Understanding density and high density",Designing high-density cities for social and environmental sustainability, 2010: 3-17.

5. Bradford, Chris. "Density calculations for US urbanized areas, weighted by census tract." Austin Contrarian 24, 2008

6. $\quad$ Eidlin, Eric. "What Density Doesn't Tell Us About Sprawl." Access Magazine, 1(37), 2010: 2-9.

7. Forsyth, A. "Measuring density: Working definitions for residential density and building intensity", Design Brief 8." Minneapolis, mn: University of Minnesota, 2003.

8. Friedman, Avi, "Fundamentals of sustainable neighbourhoods" Springer, 2014.

9. Gary Barnes. "Population and Employment Density and Travel Behavior in Large U.S. Cities." Minnesota Department of Transportation, September, 2001.

10. Hauke Jan, Kossowski Tomasz, “Comparison of values of pearson's and spearman's correlation coefficients on the same sets of data", Quaestiones Geographicae 30(2), 2011.

11. Breheny, Michael. "Urban compaction: feasible and acceptable?." Cities 14.4, 1997: 209-217.

12. Paul Clarke, "Metricity: Exploring New Measures of Urban Density", Unpublished Research Carried Out at the Royal College of Art, Helen Hamlyn Centre, 2008

13. Peter Paul van Loon, Rein de Graf, "Sustainability and urban density: a decision based design approach", proceedings of Conference On Management And Innovation For A Sustainable built environment, Amsterdam, Netherlands, ISBN: 9789052693958, 2011

14. Rapoport, Amos, "Toward a redefinition of density." Environment and Behavior ed. 7.2, 1975: 133.

15. $\mathrm{Ng}$, Edward, ed. Designing high-density cities: for social and environmental sustainability. Routledge, 2009.

16. Spearman C.E, "The proof and measurement of association between two things", American Journal of Psychology 15, 1904: 72-101

17. TCL Chuang, "Understanding residential density: The relationship between policy, measure and perception", Unpublished Master's thesis, Dept. of Urban studies and Planning, MIT , 2004

18. Whitehead, Christine M E, "The density debate: a personal view", London School of Economics and Political Science, Geography and Environment, London, UK, 2012 available at http://documents.tips/documents/the-density-debate-a-personal-viewchristine-whitehead-london-school-of-56bbfc807e8c3.html accessed on April 8, 2019

19. Kaufholz, Richard Peter, "Building densities; a physical volume approach", Unpublished Diss. MSc thesis Faculteit der Aarden levenswetenschappen Vrije Universiteit Amsterdam, 2004.

20. Burdett, R., and T. Travers. "Density and Urban Neighbourhoods in London" Minerva LSE research group, 2004.

21. Churchman, Arza. "Disentangling the concept of density." Journal of planning literature 13.4 , 1999: 389-411.

22. Roberts, Brian H. "Changes in urban density: its implications on the sustainable development of Australian cities." Proceedings of the State of Australian Cities National Conference. 2007. 